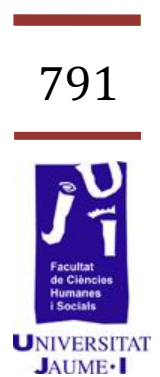

\title{
La traducción del slang en Jackie Brown (Tarantino, 1997)
}

\author{
Ana Tamayo Masero \\ tamayoa@uji.es
}




\section{Resumen}

El uso y la creación del slang han sido ampliamente estudiados tanto desde el punto de vista de la lingüística como de la traducción. Este resulta ser un ámbito de estudio candente, en tanto que el uso y la creación del slang deben su origen a, y están estrechamente vinculados con, la sociedad y sus individuos. Además, se trata de un ámbito de estudio muy complejo $y$, en muchas ocasiones, el acercamiento a dicho fenómeno es bastante subjetivo.

Este estudio analiza cualitativa y cuantitativamente, y desde una metodología descriptiva e interdisciplinaria, las muestras de slang extraídas de la película Jackie Brown (Tarantino, 1997) en su versión original y en su versión doblada al español. Se basa en conceptos como la norma de traducción y la carga pragmática, y en los enfoques lingüístico-textual, funcionalista y pragmático para arrojar luz a los Estudios de Traducción sobre un problema traductológico muy común: el de la variación lingüística.

La recopilación de datos se presenta en una ficha de trabajo y, desde un enfoque funcional y pragmático se analizan las posibles pérdidas o ganancias de las muestras en particular y de las escenas y el filme en general. Las muestras del doblaje se analizan en tres bloques, a saber, las muestras homofuncionales, las muestras con pérdida de carga pragmática respecto al texto meta y las muestras con ganancia de carga pragmática respecto al texto meta. A partir del análisis cualitativo y cuantitativo de los datos se derivan conclusiones generales sobre la traducción del slang en el corpus para ahondar en los estudios descriptivos de la traducción.

Además, se presentan propuestas de posibles estudios futuros similares a este que lo complementen y que sirvan para ir más allá en los estudios descriptivos de la traducción.

Palabras clave: slang, variación lingüística, recompensa pragmática, traducción audiovisual, doblaje

\section{Introducción}

El término slang está asociado a ciertos estereotipos, clases o grupos sociales e, incluso, a razas o edades $y$, por eso, su estudio ha sido siempre difícil de afrontar. Para llevar a cabo la presente investigación, es necesario comenzar con una definición y caracterización del término. Eble define el slang como «an ever changing set of colloquial words and phrases that speakers use to establish or reinforce social identity or cohesiveness in society at large» (1996: 11). En este trabajo se adoptará esta definición del término slang propuesta por Eble como punto de partida y así será como se entenderá dicho término a lo largo del mismo. 
En cuanto a los tipos de slang, la clasificación propuesta por Graha (2010: 21) resulta de utilidad para recopilar datos desde un enfoque lingüístico y textual. Este autor clasifica el slang de acuerdo con su evolución, esto es, de acuerdo con los procedimientos que pueden observarse en comparación con el lenguaje estándar. En este sentido, Graha apunta que el slang puede surgir de (1) un procedimiento sintáctico (como se puede ver, por ejemplo en ain't got nothing) o de (2) un procedimiento léxico, que puede ser (a) semántico (como se puede ver, por ejemplo en motherfucker) o (b) formal (como se puede ver, por ejemplo en kinda).

Sin embargo, este enfoque puramente lingüístico no es suficiente para comprender los diferentes tipos de slang desde un punto de vista traductológico, ya que ignora el contexto situacional y comunicativo en el que se da esta variación lingüística. A este respecto, la taxonomía presentada por Mayoral (1990: 36) complementa el enfoque lingüístico arriba mencionado. En su propuesta, este autor distingue entre variedades según el medio, la actitud, el origen geográfico o étnico, el individuo, el sexo, la edad, el tiempo, la posición socioeconómica o cultural, la profesión, el tema y el género o tipo de texto (Mayoral, 1990: 36). Ambas taxonomías son complementarias y útiles para la recopilación de datos desde un enfoque tanto lingüístico como contextual y situacional.

Una vez identificados los diferentes tipos de slang que pueden aparecer en el corpus, es necesario reflexionar sobre por qué se usa el slang, esto es, qué funciones puede cumplir dentro de un texto audiovisual. Para tal efecto resulta útil la taxonomía sintetizada de Eriksen, que caracteriza el slang según su función. Este autor señala que el slang puede usarse para:

\footnotetext{
$>$ Establish group relations and identity

$>$ Separate one group of people from another

$>$ Rebel against standard language through the use of words and expressions that are not defined in standard language

$>$ Lead a conversation towards informality

$>$ Suggest 'insider-knowledge' with the people to whom you are speaking

$>$ Show the speaker's attitude through the use of words and expressions that differ from standard language. Eriksen (2010: 25-26).
}

No obstante, no basta con saber qué es el slang, cómo puede formarse y para qué puede usarse. En la presente investigación, es necesario abordar el término desde un punto de vista traductológico. Dentro de los Estudios de Traducción, el estudio del slang siempre ha resultado de gran interés, ya que se trata de un tipo de variación lingüística que muestra y, a la vez, surge de un comportamiento cultural específico que puede afectar a la manera en la que el receptor reacciona al mensaje. Así, las restricciones o problemas que se derivan de la traducción del slang pueden llevar a un texto meta (TM) que no cumpla las mismas funciones que el texto origen (TO). Atendiendo a estas consideraciones, Eriksen cuestiona aspectos interesantes cuando 
aborda el estudio del slang dentro de los Estudios Descriptivos de la Traducción (DTS):

Slang seems to be connected to the culture in which it is created, so how are slang words and expressions transferred into another language and culture and does the transfer affect the possibility to maintain the use of slang in the translation? (2010: 6).

Las escuelas lingüísticas que predominaron en la disciplina hasta la década de los 70 del siglo pasado consideraban algunos rasgos del lenguaje (como el slang) intraducibles. Esta consideración, sin embargo, ya no encaja dentro del paradigma actual de los DTS. Todo texto y sus diálogos son parte de un contexto específico. Estos textos y diálogos pueden resultar más o menos ajenos a la cultura meta y mostrarán más o menos problemas traductológicos que harán que el proceso de traducción sea más o menos complicado. En la mayoría de casos no se alcanzará una equivalencia perfecta, tal y como se entendía el concepto de equivalencia antes de los DTS, no obstante, esto no da pie a afirmar que el texto y el contexto en el que se sitúa son intraducibles. El hecho de que la traducción se haya llevado a cabo diariamente y haya servido como una herramienta fundamental para la comunicación humana desde tiempos inmemoriales es la mejor prueba de que todo texto puede expresarse en base a las herramientas o medios de otro idioma, si bien es cierto que puede aparecer algún tipo de pérdida (pragmática, humorística, semántica...) en comparación con el TO, algo que, por cierto, es inherente a la traducción. El proceso de traducción, pues, será una constante toma de decisiones $y$, en este sentido, no podemos hablar de buenas o malas traducciones, sino de diferentes soluciones traductológicas a los problemas planteados por el texto que tendrán más o menos ventajas o desventajas y que seguirán o se desviarán de las normas de traducción que imperan en un determinado espacio y tiempo.

\section{Objetivos}

Los objetivos específicos de este trabajo podrían resumirse de la siguiente manera:

$>$ Delimitar el tipo de slang que aparece en el largometraje.

$>$ Estudiar de qué manera un tipo de slang es asociable a ciertas técnicas de traducción general o técnicas de traducción de la variación lingüística.

$>$ Estudiar la función que cumple el slang en la película original y analizar si existe una homofuncionalidad en la versión doblada.

$>$ Especular sobre qué ventajas o desventajas puede tener la jerarquización de ciertas prioridades o el uso de ciertas técnicas de traducción.

$>$ Analizar la repercusión de todas estas cuestiones en la recepción del filme en la cultura meta.

$>$ Servir de base para otros estudios descriptivos sobre el slang en textos audiovisuales. 
En el estudio que aquí se presenta, se ha adoptado un enfoque interdisciplinario e integrador que pueda dar cuenta de la subjetividad e interdisciplinariedad de la tarea traductora. En consecuencia, y siempre estableciendo la metodología descriptivista como punto de partida, se han tenido en cuenta diferentes modelos de investigación que, en conjunto, pueden arrojar luz sobre la complejidad del texto audiovisual y su traducción.

El modelo lingüístico y textual resulta útil para analizar, a nivel microtextual, los cambios a los que se somete la traducción para determinar qué técnica general de traducción se ha usado en cada segmento. A nivel textual, este modelo aporta las bases para analizar qué técnica de traducción para la variación lingüística se ha usado en cada caso. El concepto y caracterización de las técnicas de traducción se discutirá más adelante en este artículo.

El enfoque lingüístico y textual se ha complementado, en este estudio, con el modelo funcional o Skopostheorie, que se basa en la presunción de que toda traducción es una acción y, por definición, toda acción conlleva una intención (Vermeer, 2000: 221). El análisis contrastivo del TO y TM mostrará si la intención de ambos textos es igual o difiere. Sobre las bases de las ideas expuestas, hablaremos de un TM homofuncional cuando este cumpla la misma función, el mismo skopos, que el TO. Parece evidente que no todos los segmentos serán homofuncionales, ya que algunos aspectos del lenguaje, inevitablemente, pueden perderse en la traducción, debido, en parte, a los obstáculos impuestos por el texto. Esto, sin embargo, no significa, necesariamente, que la función o intención global del TO no pueda mantenerse. En otras palabras, los obstáculos que afectan a todo texto y a su traducción conllevan a la necesidad de establecer un orden jerárquico de prioridades (globales y locales) para superar dichos obstáculos y mantener la intención principal del texto en mente (Zabalbeascoa, 1996). Por otro lado, puede darse el caso de que el TM no cumpla la misma función que el TO (bien porque se ha establecido así en el encargo de traducción o bien porque se ha perdido demasiado en el proceso traductológico). En este caso, estaríamos ante un TM heterofuncional respecto al TO. Este estudio, pues, está también en parte basado en la Skopostheorie en tanto que se pretende determinar la intención, función o skopos, de cada segmento analizado tanto en la versión original como en la doblada. De acuerdo con lo expuesto, entiendo que la intención general del TM guiará las soluciones traductológicas durante todo el texto.

Para entender los problemas, o restricciones, que pueden hacer que el TM no comparta la misma función que el TO, el concepto de restricción se discutirá más adelante en este artículo, así como la taxonomía usada para clasificar las restricciones que aparecen en los segmentos que contienen slang en el corpus. 
Los enfoques lingüístico, textual y funcional mencionados más arriba se complementan, por último, con el modelo pragmático. Autores como Leech (1983) y Sperber y Wilson (1986) han estudiado el concepto de pragmática y lo han visto como un subcampo de la lingüística que tiene que ver con cómo las personas comprenden y producen el discurso en una situación comunicativa concreta. Estos autores han diferenciado dos intenciones en todo discurso, a saber, la intención informativa (o significado del texto) y la intención comunicativa (o significado del interlocutor). Martínez Sierra (2008) ve, en este enfoque, herramientas de análisis que pueden resultar de utilidad para los Estudios de Traducción. Este autor define la pragmática como la rama que estudia (1) los actos sociales e interpersonales cuando el lenguaje está involucrado, (2) la relación entre el lenguaje y su contexto y (3) los sistemas de conocimiento compartido que hacen posible la comunicación. Desde este punto de vista, hay una clara necesidad de que el emisor y el receptor compartan algún tipo de información previa sobre el mundo que haga que la comunicación sea posible. Cuando entra en juego la traducción, el texto se dirige a un segundo receptor $y$, como consecuencia, la información que el emisor y el receptor original compartían puede que ya no sea compartida por el nuevo receptor. Esto puede conllevar un mayor procesamiento de la información $y$, sin embargo, este mayor procesamiento de la información no lleva, necesariamente, a un efecto cognitivo mayor. Como se puede inferir, cuanta más información compartan los agentes involucrados en la comunicación, más posibilidades habrá de que la información tenga una relevancia similar $y$, por tanto, una recompensa pragmática similar en el receptor. El término recompensa pragmática se entiende en este artículo como el resultado obtenido por el receptor de un texto mediante el esfuerzo cognitivo llevado a cabo para procesar la información y entender la intención comunicativa de dicho texto (basado en Martínez Sierra, 2008). Este enfoque ha ayudado a segmentar los datos en diferentes categorías teniendo en cuenta las posibles pérdidas o ganancias en la recompensa pragmática de cada muestra.

Para el presente estudio, hay dos nociones básicas de los estudios de TAV para el análisis del TM. En la siguiente subsección se discuten los conceptos de técnica de traducción y restricción, así como las taxonomías usadas al respecto en la investigación que aquí se presenta.

\section{Técnicas de traducción}

Una comparación entre TO y TM revela, a nivel microtextual, la técnica de traducción usada para traducir el segmento que contiene slang. Vinay y Darbelnet (1958) fueron los primeros estudiosos en introducir este concepto en el campo de la estilística comparada. En relación a lo expuesto, se puede afirmar que el modelo lingüísticotextual arriba mencionado se centra en el concepto de técnicas de 
traducción tomando la estilística comparada como punto de partida. Dentro de este modelo Hurtado (2001: 268-271) propone un listado de 18 técnicas que pueden observarse mediante una comparación entre el TO y TM. Martí Ferriol (2010: 92-94), por su parte, toma esta clasificación de técnicas generales de traducción y la adapta a las particularidades de la TAV. Así, este autor propone una lista de 20 técnicas: préstamo, calco, traducción palabra por palabra, traducción uno por uno, traducción literal, equivalente acuñado, omisión, reducción, compresión, particularización, generalización, transposición, descripción, ampliación, amplificación, modulación, variación, sustitución, adaptación y creación discursiva. ${ }^{1}$ Cabe destacar que, si bien las técnicas de traducción pueden deducirse por mera observación de ambos textos, TO y TM, su clasificación no debería entenderse como un listado rígido e inalterable. Algunas traducciones pueden encajar dentro de una u otra técnica $o$, incluso, pueden situarse a medio camino entre dos técnicas. En el presente estudio, se ha permitido una cierta flexibilidad a la hora de clasificar las traducciones según las técnicas de traducción, ya que el propio acto de traducir y su estudio no abogan por fronteras rígidas.

Las técnicas de traducción usadas para traducir el slang, entendiendo el slang como un problema específico con posibles soluciones específicas, también han dado pie a debates dentro de los DTS. Marco (2002) habla de técnicas para la traducción de la variación lingüística en traducción literaria. En este estudio, el slang se considera un tipo de variación lingüística y, atendiendo a tales consideraciones, la clasificación propuesta por Marco (2002), si bien fue originalmente concebida para la traducción literaria, encaja perfectamente dentro de los estudios de TAV. Este autor propone tres pares dicotómicos de técnicas para la traducción de la variación lingüística:

(1) Traducciones con o sin marcas de variación lingüística: la primera opción implicaría una intención de recrear aspectos de la lengua origen que difieren del lenguaje estándar (sin que conlleve, necesariamente, el uso de lenguaje incorrecto), mientras que la segunda opción implicaría una traducción en lenguaje estándar.

(2) Traducciones con o sin transgresión lingüística: la primera opción conlleva algún tipo de transgresión de la norma lingüística aceptada, esto es, algún tipo de lenguaje no normativo. La segunda opción, por su parte, implicaría un lenguaje normativo, esto es, un lenguaje compuesto por diálogos completamente correctos según la norma lingüística.

(3) Traducciones convencionales o naturales: una traducción convencional implica que el texto no se puede asociar con ninguna variación lingüística que pueda encontrarse de forma natural, esto es, la traducción es un texto mixto con rasgos dialectales de diferentes

\footnotetext{
${ }^{1}$ Para una definición y caracterización más extensiva de cada técnica véase Hurtado y Molina (2002) y Martí Ferriol (2007 y 2010).
} 
orígenes. La traducción natural, por su parte, intenta recrear un lenguaje real con una variación lingüística que puede encontrarse en la cultura meta, esto es, usa dialectos reales de la lengua meta.

La presencia de estas técnicas de traducción de la variación lingüística se ha tenido en cuenta para recopilar datos de los segmentos que contienen slang.

\section{Restricciones}

En el presente estudio, las restricciones o problemas de traducción se entienden como los obstáculos impuestos por el texto que impiden una traducción literal o natural para un segmento determinado. En este sentido, estas restricciones pueden afectar a las estrategias y técnicas de traducción empleadas para traducir un segmento en concreto. Es más, la presencia de estas restricciones puede, en última instancia, llevar a soluciones de traducción que crean un TM heterofuncional respecto al TO, cuando se pretendía conseguir una traducción homofuncional. Puesto que el texto audiovisual tiene la particularidad de transferir información mediante dos canales diferentes (el visual y el auditivo), es necesario considerar los problemas específicos que la transferencia mediante dos canales de información puede conllevar. En este sentido, Martí Ferriol (2007, 2010) propone una taxonomía de cinco restricciones adaptadas a los textos audiovisuales y su traducción:

(1) restricciones profesionales, «imposed by the work conditions a translator must meet, depending on the execution of a certain assignment» (Martí Ferriol, 2007: 176);

(2) restricciones formales, «inherent to the professional techniques and practices due in dubbing and subtitling» (Martí Ferriol, 2007: 176); (3) restricciones lingüísticas, «associated with dialectal variation, idiolects, registers, spoken language» (Martí Ferriol, 2007: 176);

(4) restricciones semióticas o icónicas «associated with filmic language and of semiotic type» (Martí Ferriol, 2007: 176) y

(5) restricciones socioculturales «due to the simultaneous existence of different cultural systems in the linguistic and iconic messages» (Martí Ferriol, 2007: 176).

En este estudio, toda muestra con slang tiene, por definición una restricción lingüística. Sin embargo, es de mayúscula importancia analizar si esta restricción lingüística se ve agravada con la presencia de otro tipo de restricciones para, así, poder evaluar las posibles explicaciones para soluciones recurrentes en la traducción (por ejemplo, pérdidas, compensaciones, etc.). Martí Ferriol también propone un caso de "restricción nula» (2007: 176) para aquellos segmentos en los que no se observa ningún tipo de restricción. Este no será el caso de ninguna de las muestras analizadas para esta 
investigación, ya que todas mostrarán, como mínimo, una restricción lingüística impuesta por la presencia de la variación lingüística, esto es, impuesta por la presencia de rasgos inherentes sub-estándar que caracterizan el slang.

La metodología adoptada para este estudio, basada en todos los enfoques y conceptos arriba mencionados, se ha llevado a cabo mediante un análisis cualitativo y cuantitativo de los datos. Los datos se han recogido mediante el visionado de la película original y la doblada y comparando ambas versiones en la tabla que se presenta a continuación. Esta tabla está basada en un modelo diseñado por Martínez Sierra (2008):

Tabla 1. Tabla para la recogida de datos

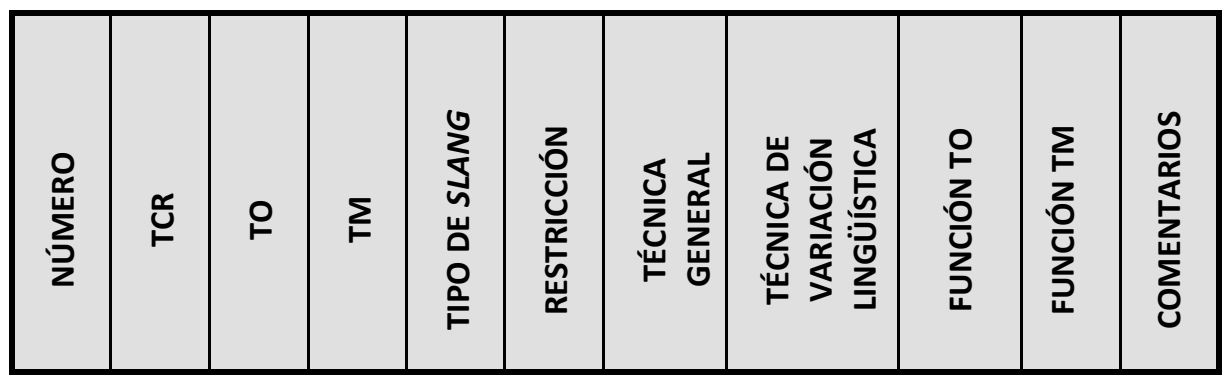

La información y variables incluidas en esta tabla han ayudado a inferir normas de traducción (Toury, 1999) mediante el análisis cualitativo según las técnicas de traducción observadas para, así, poder determinar la homofuncionalidad o heterofuncionalidad de la versión doblada con respecto a la versión original. El análisis cuantitativo de los datos ha sido de utilidad para determinar la frecuencia de uso de algunas técnicas o la frecuencia de aparición de segmentos homofuncionales. En este sentido, cuando una técnica de traducción se observa repetidamente durante toda la traducción, puede indicar que hay una norma de traducción del slang para doblaje. Sin embargo, esta indicación debe validarse con otros estudios similares a este. La frecuencia de uso de algunas técnicas será relevante para determinar técnicas, estrategias y método de traducción utilizados. La tabla usada para el análisis incluye la siguiente información:

NÚMERO $\rightarrow$ Número de la muestra. Todas las muestras han sido numeradas según orden de aparición en el filme.

TCR $\rightarrow$ Siglas de Time Code Recording. Es el momento exacto en el que aparece la muestra en el filme, tiene el formato hh:mm:ss.

TO $\rightarrow$ Texto origen (en inglés) de la muestra.

TM $\rightarrow$ Texto meta (en español) de la muestra.

TIPO DE SLANG $\rightarrow$ Basado en las taxonomías de Graha (2010: 21) y Mayoral (1990:36). Véase sección 2. Introducción. 
RESTRICCIÓN $\rightarrow$ Basado en la taxonomía de Martí Ferriol (2010: 83-86). Véase sección 4. Material y método, subsección Restricciones.

TÉCNICA GENERAL $\rightarrow$ Basado en la clasificación de 20 técnicas de traducción de Martí Ferriol (2010). Véase sección 4. Material y método, subsección Técnicas de traducción.

TÉCNICA DE VARIACIÓN LINGÜÍSTICA $\rightarrow$ Basado en la clasificación de Marco (2002). Véase sección 4. Material y método, subsección Técnicas de traducción.

$\rightarrow$ FUNCIÓN TO $\rightarrow$ Se refiere a la función específica que cumple el slang en la muestra. Basado en Eriksen (2010: 25-26). Véase sección 2. Introducción.

FUNCIÓN TM $\rightarrow$ Se refiere a la función específica que cumple el slang en la muestra y si esta función es homofuncional con respecto al TO. Las pérdidas o ganancias de recompensa pragmática respecto al TO también son objeto de discusión.

COMENTARIOS $\rightarrow$ En esta columna se incluyen comentarios relevantes para aquellas muestras en las que pueden ser útiles para el análisis cualitativo.

\section{Corpus}

Dado el alcance de este estudio, el análisis del slang y su traducción en largometrajes se llevará a cabo solamente en una película. Los resultados del análisis servirán, sin embargo, como una muestra que permita elaborar hipótesis para trabajos de mayor envergadura. En el futuro, sería interesante analizar un corpus más extenso de películas de este mismo director o de este mismo género, para poder extraer conclusiones más significativas y ser capaces de enunciar normas de traducción.

Quentin Tarantino es uno de los directores más influyentes de la década de los 90 del siglo pasado y de la primera década del siglo XXI. Este director y sus películas son dignos de estudio, por ejemplo y entre otros motivos, por las estructuras temporales tan sugestivas, por el dominio del espacio cinematográfico, por los mensajes escondidos en los escenarios, por el uso de los diferentes planos cinematográficos y de los colores, por las alusiones a la cultura pop y, sobre todo, por la peculiaridad, imaginación e innovación de las películas.

Este film resulta ser un constante ir y venir de situaciones entre policías y traficantes de armas. Hay, pues, dos grupos sociales claramente diferenciados, que mostrarán en la película formas de hablar y slang diferente. Es más, la actriz protagonista se ve involucrada en ambos grupos sociales, lo que le llevará a adaptarse al slang de ambos grupos para identificarse con los mismos.

Por otro lado, esta película de Tarantino está considerada como su film de blaxploitation. La blaxploitation es un movimiento cinematográfico con origen en Estados Unidos en la década de los 70 del siglo pasado y que tiene a la comunidad de negros afroamericanos 
como figura principal. Este movimiento hizo que aumentara el número de actores y espectadores afroamericanos y surgiera, incluso, un género musical específico asociado a estos filmes. Samuel L. Jackson y, sobre todo, Pam Grier - considerada la musa de este género fílmicoson dos actores que representan este movimiento y género en Jackie Brown. En el análisis del slang de la película, por consiguiente, se espera encontrar términos y fraseología específica de, y asociada con, la comunidad afroamericana de Estados Unidos.

Todas estas consideraciones llevan a asumir que el largometraje contendrá slang, fraseología y términos específicos que pueden asociarse a grupos sociales específicos de la comunidad afroamericana de los Estados Unidos. Pero no solo eso, el hecho de que este grupo social no exista como comunidad en la cultura meta ha sido un punto crucial para decidir llevar a cabo el estudio en esta película en particular. Es interesante estudiar cómo un lenguaje específico asociable a un grupo social específico se traduce para una cultura en la que dicho grupo social no existe.

Del corpus se han recopilado un total de 378 muestras con slang. Los datos se han almacenado en la tabla presentada más arriba y teniendo en cuenta todos los enfoques traductológicos ya mencionados. Después, las muestras se han dividido en tres tablas diferentes dependiendo de la función del TM en comparación con el TO. Así, la primera tabla presenta las muestras en las que el TM es homofuncional respecto al TO, la segunda tabla presenta las muestras en las que el TM pierde carga pragmática y la tercera tabla presenta las muestras en las que el TM gana carga pragmática. El análisis de las tres tablas se explica al detalle en la siguiente sección.

\section{Resultados}

Como se menciona más arriba, los datos se han dividido en tres tablas. En la primera tabla hay muestras en las que el TM es homofuncional, esto es, tiene la misma intención y cumple la misma función que el TO. En la segunda tabla hay muestras en las que la versión doblada ha perdido carga pragmática. En otras palabras, la recompensa pragmática que alcanza el receptor original no la puede alcanzar el receptor de la versión doblada debido a la presencia del slang. Por último, en la tercera tabla hay muestras en las que el TM presenta una carga pragmática añadida, esto es, la recompensa pragmática alcanzada por el receptor de la versión doblada es mayor que la del receptor original.

Soy consciente de las limitaciones de esta investigación y considero que los resultados ofrecidos en este estudio deberían ser validados con un estudio de recepción que aporte datos reales sobre la recompensa obtenida por los receptores del texto original y el doblado. Este tipo de estudio podrá llevarse a cabo en el futuro pero, 
por el momento, esta investigación se limita al estudio de los segmentos que contienen slang desde un punto de vista pragmático.

\section{Muestras en las que el TM es Homunfuncional respecto al TO}

De las 378 muestras extraídas del largometraje 238 muestran una homofuncionalidad del segmento del TM respecto al segmento del TO. Esto supone un $63 \%$ de las muestras analizadas. Las técnicas usadas con más frecuencia son el equivalente acuñado ${ }^{2}$ (152 casos), la creación discursiva ${ }^{3}$ (96 casos) y la modulación ${ }^{4}$ ( 76 casos).

Tanto la creación discursiva como la modulación son técnicas usadas para conseguir un equivalente funcional ( $y$ no un equivalente lingüístico) respecto al TO, esto es, el traductor intenta conseguir, mediante el uso de estas técnicas, una reacción similar, una recompensa pragmática similar, por parte del receptor de la versión doblada. Esta constante búsqueda de un equivalente funcional y pragmático hace que ambos textos sean homofuncionales.

También se observa que, en algunos segmentos, se usan técnicas compensatorias. En otras palabras, la hipotética pérdida que puede asignarse a algunas técnicas como la reducción (por ejemplo en la traducción de "l ain't saying nothing...» por "No te he dicho...») puede ser compensada con el uso de otras técnicas como la ampliación (por ejemplo en la traducción de "...about you shooting anybody" por "...que te cargues a nadie») dentro de un mismo segmento. Esto es, el hecho de que se observe una técnica que implique pérdida de funcionalidad no significa que toda la muestra pierda la funcionalidad si esa pérdida puede compensarse por otros medios.

En las 378 muestras solo se observan 12 casos de transgresión lingüística (véase sección 4. Material y método, subsección Técnicas de traducción) en el TM, mientras que hay muchísimos casos de transgresión en el TO, casi todos vinculables al slang que surge de un procedimiento sintáctico y de una posición social específica. Estas transgresiones lingüísticas resultan ser difíciles de transferir a otra lengua, puesto que son parte de una cultura y su transferencia terminaría por producir un TM demasiado familiarizante. Una vez más, la modulación y la creación discursiva son las técnicas más usadas para compensar la dificultad de mostrar transgresiones lingüísticas en el TM sin optar por estrategias demasiado familiarizantes que podrían causar una reacción no deseada en el receptor meta.

En la Tabla 2 se muestran algunos segmentos homofuncionales. Las palabras o expresiones subrayadas se refieren al slang que aparece en la película.

\footnotetext{
${ }^{2}$ Que consiste en «to use a term or expression recognized (by dictionaries or language in use) as an equivalent in the target language.» (Hurtado y Molina, 2002: 510).

${ }^{3}$ Que consiste en "to establish a temporary equivalence that is totally unpredictable out of context.» (Hurtado y Molina, 2002: 510).

${ }^{4}$ Que consiste en «to change the point of view, focus or cognitive category in relation to the ST; it can be lexical or structural.» (Hurtado y Molina, 2002: 510).
} 
Tabla 2. Muestras en las que el TM es homofuncional

\begin{tabular}{|c|c|c|c|}
\hline NÚMERO & 37 & 48 & 83 \\
\hline TCR & $00: 11: 40$ & $00: 13: 33$ & $00: 18: 29$ \\
\hline TO & $\begin{array}{l}\text { Man, he's a big one. } \\
\text { You're all tight? }\end{array}$ & $\begin{array}{l}\text { You ain't got to do } \\
\text { nothing, man. }\end{array}$ & $\begin{array}{l}\text { All you have to do is lay in } \\
\text { here and hold on to this } \\
\text { motherfucker, alright? And } \\
\text { I'm going to tell them I'm } \\
\text { opening up my trunk to } \\
\text { show 'em my goods. I open } \\
\text { up the trunk, you pop up, } \\
\text { rack this motherfucker. }\end{array}$ \\
\hline TM & $\begin{array}{c}\text { Joder, qué grande es. } \\
\text { ¿Sois colegas? }\end{array}$ & Está tirado, tío & $\begin{array}{l}\text { Mira, negro, sólo tienes que } \\
\text { tumbarte ahí dentro con } \\
\text { esta belleza en tus manos, } \\
\text { ¿vale? Les diré que llevo la } \\
\text { mercancía en el maletero y } \\
\text { en cuanto lo abra, les } \\
\text { apuntas y cargas esta hija } \\
\text { de puta. }\end{array}$ \\
\hline TIPO DE SLANG & $\begin{array}{l}\text { Procedimiento léxico } \\
\text { semántico y } \\
\text { procedimiento sintáctico } \\
\text { Variedad según posición e } \\
\text { individuo }\end{array}$ & $\begin{array}{l}\text { Procedimiento } \\
\text { sintáctico } \\
\text { Variedad según } \\
\text { posición, actitud e } \\
\text { individuo }\end{array}$ & $\begin{array}{l}\text { Procedimiento sintáctico y } \\
\text { procedimiento léxico } \\
\text { semántico } \\
\text { Variedad según posición, } \\
\text { actitud e individuo }\end{array}$ \\
\hline RESTRICCIÓN & - & - & - \\
\hline $\begin{array}{l}\text { TÉCNICA } \\
\text { GENERAL }\end{array}$ & $\begin{array}{l}\text { Modulación (joder) } \\
\text { Creación discursiva (¿Sois } \\
\text { colegas?) }\end{array}$ & $\begin{array}{l}\text { Creación discursiva } \\
\text { (Está tirado) }\end{array}$ & $\begin{array}{c}\text { Ampliación (negro) } \\
\text { Modulación (belleza) } \\
\text { Equivalente acuñado (hija } \\
\text { de puta) }\end{array}$ \\
\hline $\begin{array}{l}\text { TÉCNICA DE } \\
\text { VARIACIÓN } \\
\text { LINGÜÍSTICA }\end{array}$ & $\begin{array}{c}\text { Sin marcas } \\
\text { Sin transgresión } \\
\text { Natural }\end{array}$ & $\begin{array}{c}\text { Con marcas } \\
\text { Sin transgresión } \\
\text { Natural }\end{array}$ & $\begin{array}{c}\text { Con marcas } \\
\text { Sin transgresión } \\
\text { Natural }\end{array}$ \\
\hline FUNCIÓN TO & $\begin{array}{l}\text { Separate one group } \\
\text { of people from } \\
\text { another Rebel against } \\
\text { standard language }\end{array}$ & $\begin{array}{l}\text { Show the speaker's } \\
\text { attitude through the } \\
\text { use of words and } \\
\text { expressions that differ } \\
\text { from standard } \\
\text { Language }\end{array}$ & $\begin{array}{l}\text { Show the speaker's attitude } \\
\text { through the use of words } \\
\text { and expressions that differ } \\
\text { from standard Language }\end{array}$ \\
\hline FUNCIÓN TM & TM es homofuncional & TM es homofuncional & TM es homofuncional \\
\hline COMENTARIOS & $\begin{array}{l}\text { La modulación ayuda a } \\
\text { mantener la funcionalidad }\end{array}$ & $\begin{array}{c}\text { Traducción muy } \\
\text { natural }\end{array}$ & $\begin{array}{c}\text { La traducción de } \\
\text { «motherfucker» por } \\
\text { «belleza» ayuda a la } \\
\text { naturalidad del enunciado } \\
\text { para mantener la } \\
\text { funcionalidad }\end{array}$ \\
\hline
\end{tabular}




\section{Muestras en las que el TM presenta una pérdida en la carga pragmática}

De las 378 muestras extraídas, 103 muestras presentan una pérdida de la carga pragmática, lo que supone un $27,2 \%$ de los casos analizados. Las técnicas más presentes en las muestras en las que se observa una pérdida de carga pragmática son la reducción ${ }^{5}$ (98 casos) y el equivalente acuñado ${ }^{6,7}$ (30 casos). En las muestras analizadas para este estudio, lo que Martí Ferriol (2010) Ilama reducción se usa, en realidad, como técnica de nivelación, mediante la cual el registro del TO se eleva al nivel estándar en el TM. En 47 de estas 103 muestras la pérdida se produce, en parte o en su totalidad, por la dificultad de trasladar el slang surgido de un procedimiento sintáctico al TM.

Casi todas las muestras con pérdida de carga pragmática presentan una traducción convencional y sin marcas de variación lingüística (92 de las 103 muestras). Esta traducción convencional, en ocasiones, se presenta mediante un tipo de lenguaje muy típico de los textos audiovisuales traducidos, pero raramente presente en situaciones comunicativas reales, lo que Chaume llama translationese (2004: 175).

Algunas de estas pérdidas están justificadas por la presencia de otras restricciones además de la restricción lingüística inherente a todas las muestras con slang. Casi todas estas restricciones son restricciones formales.

Cabe comentar que el contexto sociocultural en el que se sitúa el filme no puede ser modificado por el traductor y las situaciones comunicativas que se dan en el largometraje no siempre encuentran un equivalente funcional que encaje en la cultura meta. Esta es la razón por la que algunas muestras del TM no se acoplan al texto audiovisual de una manera tan perfecta como lo hacen las muestras del TO. Algunos espectadores, intuyo, entienden estos hechos cuando se disponen a ver una película de estas características. Sin embargo, esto no hace que la pérdida de carga pragmática se pueda evitar.

En la Tabla 3 se muestran algunos segmentos con pérdida de carga pragmática. Las palabras o expresiones subrayadas se refieren al slang que aparece en la película.

\footnotetext{
${ }^{5}$ Que consiste en «To suppress a ST information item in the TT.» (Hurtado y Molina, 2002: 510).

${ }^{6}$ Que consiste en «To use a term or expression recognized (by dictionaries or language in use) as an equivalent in the TL.» (Hurtado y Molina, 2002: 510).

${ }^{7}$ Esta técnica de traducción también puede implicar una pérdida de la carga pragmática en tanto que, en ocasiones, el término elegido en la lengua meta puede ser un equivalente informativo (puede aparecer como equivalente en un diccionario bilingüe, por ejemplo) pero puede que no cumpla la misma intención comunicativa que el término en la lengua origen.
} 
Tabla 3. Muestras en las que el TM pierde carga pragmática

\begin{tabular}{|c|c|c|c|c|}
\hline NÚMERO & 52 & 81 & 88 & 148 \\
\hline TCR & $00: 14: 26$ & $00: 18: 12$ & $00: 18: 52$ & $00: 46: 07$ \\
\hline TO & $\begin{array}{l}\text { He ain't gonna } \\
\text { like that. } \\
\text { Beaumont ain't } \\
\text { got a doin' time } \\
\underline{\text { kinda }} \\
\text { disposition. }\end{array}$ & $\begin{array}{l}\text { They don't want } \\
\text { no trouble. You } \\
\text { might argue } \\
\text { about price and } \\
\text { shit, but you ain't } \\
\text { gotta worry } \\
\text { about them } \\
\text { shootin' you in } \\
\text { the back }\end{array}$ & $\begin{array}{l}\text { Man, I ain't riding } \\
\text { in no godamm } \\
\text { trunk for no } \\
\text { minute, man }\end{array}$ & $\begin{array}{c}\text { The same guy } \\
\text { who put my ass } \\
\text { in jail. }\end{array}$ \\
\hline TM & $\begin{array}{l}\text { No le va a gustar } \\
\text { nada. Beaumont } \\
\text { no tiene carácter } \\
\text { para aguantar } \\
\text { una condena. }\end{array}$ & $\begin{array}{c}\text { No suelen } \\
\text { buscarse } \\
\text { problemas. A lo } \\
\text { mejor te regatean } \\
\text { un poco el precio, } \\
\text { pero no hay que } \\
\text { preocuparse por } \\
\text { si te pegan un tiro } \\
\text { por la espalda }\end{array}$ & $\begin{array}{l}\text { No pienso viajar en } \\
\text { un jodido maletero } \\
\text { ni un minuto. }\end{array}$ & $\begin{array}{l}\text { El mismo tío que } \\
\text { me metió en ella. }\end{array}$ \\
\hline TIPO DE SLANG & $\begin{array}{l}\text { Procedimiento } \\
\text { sintáctico y } \\
\text { procedimiento } \\
\text { léxico formal } \\
\text { Variedad según } \\
\text { posición, actitud } \\
\text { e individuo }\end{array}$ & $\begin{array}{l}\text { Procedimiento } \\
\text { sintáctico y } \\
\text { procedimiento } \\
\text { léxico semántico } \\
\text { Variedad según } \\
\text { posición, actitud } \\
\text { e individuo }\end{array}$ & $\begin{array}{l}\text { Procedimiento } \\
\text { sintáctico y } \\
\text { procedimiento } \\
\text { léxico semántico } \\
\text { Variedad según } \\
\text { posición, actitud, } \\
\text { individuo y sexo }\end{array}$ & $\begin{array}{l}\text { Procedimiento } \\
\text { léxico semántico } \\
\text { Variedad según } \\
\text { posición, actitud } \\
\text { e individuo }\end{array}$ \\
\hline RESTRICCIÓN & - & - & - & formal \\
\hline TÉCNICA GENERAL & $\begin{array}{l}\text { reducción (no le } \\
\text { va a gustar) } \\
\text { reducción (no } \\
\text { tiene carácter } \\
\text { para aguantar } \\
\text { una condena) }\end{array}$ & $\begin{array}{c}\text { omisión (a lo } \\
\text { mejor te regatean } \\
\text { un poco el precio) } \\
\text { reducción (pero } \\
\text { no hay que) }\end{array}$ & $\begin{array}{l}\text { reducción (no } \\
\text { pienso viajar) } \\
\text { equivalente } \\
\text { acuñado (jodido) } \\
\text { reducción (ni un } \\
\text { minuto) }\end{array}$ & $\begin{array}{l}\text { reducción (que } \\
\text { me metió) }\end{array}$ \\
\hline $\begin{array}{l}\text { TÉCNICA DE } \\
\text { VARIACIÓN } \\
\text { LINGÜÍSTICA }\end{array}$ & $\begin{array}{c}\text { Sin marcas } \\
\text { Sin transgresión } \\
\text { convencional }\end{array}$ & $\begin{array}{c}\text { con marcas } \\
\text { Sin transgresión } \\
\text { natural }\end{array}$ & $\begin{array}{c}\text { con marcas } \\
\text { Sin transgresión } \\
\text { convencional }\end{array}$ & $\begin{array}{c}\text { con marcas } \\
\text { Sin transgresión } \\
\text { natural }\end{array}$ \\
\hline
\end{tabular}




\begin{tabular}{|c|c|c|c|c|}
\hline FUNCIÓN TO & $\begin{array}{l}\text { Establish } \\
\text { group } \\
\text { relations } \\
\text { and identity }\end{array}$ & $\begin{array}{l}\text { Establish } \\
\text { group } \\
\text { relations and } \\
\text { identity }\end{array}$ & $\begin{array}{c}\text { Suggest } \\
\text { 'insider- } \\
\text { knowledge' } \\
\text { with the } \\
\text { people to } \\
\text { whom you are } \\
\text { speaking }\end{array}$ & $\begin{array}{l}\text { Show the } \\
\text { speaker's } \\
\text { attitude } \\
\text { through the } \\
\text { use of words } \\
\text { and } \\
\text { expressions } \\
\text { that differ } \\
\text { from } \\
\text { standard } \\
\text { language }\end{array}$ \\
\hline FUNCIÓN TM & $\begin{array}{c}\text { TM pierde carga } \\
\text { pragmática }\end{array}$ & $\begin{array}{c}\text { TM pierde carga } \\
\text { pragmática }\end{array}$ & $\begin{array}{c}\text { TM pierde carga } \\
\text { pragmática }\end{array}$ & $\begin{array}{c}\text { TM pierde carga } \\
\text { pragmática }\end{array}$ \\
\hline COMENTARIOS & $\begin{array}{l}\text { El slang que } \\
\text { surge de } \\
\text { procedimientos } \\
\text { sintácticos es } \\
\text { muy difícil de } \\
\text { trasladar }\end{array}$ & $\begin{array}{l}\text { Segmento } \\
\text { relativamente } \\
\text { largo con poco } \\
\text { slang en el TM en } \\
\text { comparación con } \\
\text { el TO }\end{array}$ & $\begin{array}{l}\text { El equivalente } \\
\text { acuñado «jodido» } \\
\text { resulta en una } \\
\text { traducción } \\
\text { convencional y en } \\
\text { un lenguaje fílmico } \\
\text { (translationese) ya } \\
\text { que en la cultura } \\
\text { meta este término } \\
\text { no se usa } \\
\text { habitualmente } \\
\text { como adjetivo } \\
\text { antepuesto a un } \\
\text { sustantivo }\end{array}$ & $\begin{array}{l}\text { Pérdida debido a } \\
\text { la restricción } \\
\text { formal }\end{array}$ \\
\hline
\end{tabular}

\section{Muestras en las que el TM presenta una ganancia de carga pragmática}

De las 378 muestras extraídas 37 presentan una carga pragmática añadida en el TM respecto al TO, lo que supone un 9,8\% de todas las muestras. Se observan un total de 12 casos de particularización ${ }^{8}, 11$ casos de creación discursiva ${ }^{9}, 8$ casos de ampliación ${ }^{10}$ y 8 casos de modulación ${ }^{11}$, que son las técnicas que con más frecuencia se usan. Casi todas las muestras en las que se observa una carga pragmática añadida parten de un segmento del TO en el que no se observa slang (29 de 37 muestras). Además, en el 100\% de los casos se opta por una técnica que aporte naturalidad al TM.

Habrá quien argumente que llevar a cabo una traducción en la que se gane recompensa pragmática es una opción traductológica arriesgada, ya que puede modificar la caracterización original de los personajes. No obstante, no es este el caso, puesto que las ganancias en carga pragmática se usan, en este filme, como estrategia

\footnotetext{
${ }^{8}$ Que consiste en «To use a more precise or concrete term.» (Hurtado y Molina, 2002: 510).

${ }^{9}$ Que consiste en «To establish a temporary equivalence that is totally unpredictable out of context.» (Hurtado y Molina, 2002: 510).

${ }^{10}$ Que consiste en «To introduce details that are not formulated in the ST: information,explicative paraphrasing.» (Hurtado y Molina, 2002: 510).

${ }^{11}$ Que consiste en «To change the point of view, focus or cognitive category in relation to the ST; it can be lexical or structural.» (Hurtado y Molina, 2002: 510).
} 
compensatoria para aquellos segmentos en los que una pérdida en la carga pragmática es inevitable.

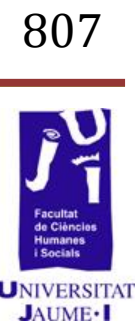

Tabla 4. Muestras en las que el TM gana carga pragmàtica

\begin{tabular}{|c|c|c|c|}
\hline NÚMERO & 113 & 119 & 195 \\
\hline TCR & $00: 27: 24$ & 00:30:02 & 01:04:06 \\
\hline TO & Bad knees & $\begin{array}{c}\text { Jackie, do you know a } \\
\text { guy named Beaumont } \\
\text { Livingston? }\end{array}$ & C'mon, don't lie \\
\hline TM & $\begin{array}{c}\text { Tengo las rodillas } \\
\text { jodidas }\end{array}$ & $\begin{array}{l}\text { Jackie, ¿conoce a un } \\
\text { tipejo llamado } \\
\text { Beaumont Livingston? }\end{array}$ & No cuela.... \\
\hline TIPO DE SLANG & - & - & - \\
\hline RESTRICCIÓN & formal & - & - \\
\hline TÉCNICA GENERAL & Ampliación (jodidas) & Particularización (tipejo) & $\begin{array}{c}\text { Modulación (no } \\
\text { cuela) }\end{array}$ \\
\hline $\begin{array}{l}\text { TÉCNICA DE } \\
\text { VARIACIÓN } \\
\text { LINGÜÍSTICA }\end{array}$ & $\begin{array}{c}\text { Con marcas } \\
\text { Sin transgresión } \\
\text { Convencional }\end{array}$ & $\begin{array}{c}\text { Con marcas } \\
\text { Sin transgresión } \\
\text { Natural }\end{array}$ & $\begin{array}{c}\text { Con marcas } \\
\text { Sin transgresión } \\
\text { Natural }\end{array}$ \\
\hline FUNCIÓN TO & - & - & - \\
\hline FUNCIÓN TM & $\begin{array}{c}\text { TM añade carga } \\
\text { pragmática }\end{array}$ & $\begin{array}{c}\text { TM añade carga } \\
\text { pragmática }\end{array}$ & $\begin{array}{c}\text { TM añade carga } \\
\text { pragmática }\end{array}$ \\
\hline COMENTARIOS & $\begin{array}{l}\text { Aunque es uno de los } \\
\text { primeros enunciados } \\
\text { de este personaje, la } \\
\text { ampliación no } \\
\text { modifica la } \\
\text { caracterización, } \\
\text { porque en otras } \\
\text { escenas posteriores } \\
\text { de este personaje, sus } \\
\text { enunciados muestran } \\
\text { un estilo similar a este }\end{array}$ & $\begin{array}{l}\text { El slang del TM sugiere } \\
\text { insider-knowledge }\end{array}$ & $\begin{array}{l}\text { TM añade la } \\
\text { función: «Show } \\
\text { the speaker's } \\
\text { attitude } \\
\text { through the use } \\
\text { of words and } \\
\text { expressions that } \\
\text { differ from } \\
\text { standard } \\
\text { language» }\end{array}$ \\
\hline
\end{tabular}

\section{Discusión y conclusiones}

Tras el análisis de los datos llevado a cabo en el apartado anterior, estoy en disposición de inferir algunas conclusiones generales que se derivan de este trabajo:

1. Según lo analizado hasta ahora, se intuye que el método usado para la traducción según la taxonomía de Hurtado (2001: 252-253) es el interpretativo-comunicativo. Haría falta un 
análisis exhaustivo de los demás problemas de traducción del largometraje para poder afirmarlo.

2. A rasgos generales, se trata de una traducción homofuncional donde se prioriza la naturalidad de los enunciados.

3. Las técnicas más usadas para mantener la funcionalidad del TO son la creación discursiva, la modulación y el equivalente acuñado.

4. Las pérdidas de carga pragmática en el TM se producen, en su mayoría, por la dificultad de trasladar el slang surgido de determinados procedimientos (como procedimientos sintácticos como ain't, como la falta de sujeto al principio o procedimientos léxicos formales o como la apócope o la aféresis en fella, gonna, ya o nigga), por optar por una traducción convencional y sin marcas y/o por el uso de la técnica de reducción.

5. Las pérdidas concretas en la carga pragmática de segmentos determinados no suponen una pérdida en la funcionalidad de la escena a la que pertenecen ni de la película. 6. Los segmentos con carga pragmática añadida pretenden ser una estrategia compensatoria para los segmentos donde hay una pérdida, y no suponen un cambio en la caracterización de los personajes.

7. El hecho de que se observen pocas transgresiones lingüísticas en el TM hace que la traducción no resulte excesivamente familiarizante, algo que no encajaría con el contexto sociocultural en el que se enmarca la historia.

8. Las pocas transgresiones observadas sirven para compensar pérdidas en la carga pragmática o para mantener la funcionalidad de determinados segmentos con mucha variación lingüística en el TO.

De cada conclusión puede derivarse una norma de traducción que dé cuenta de las prioridades establecidas $y$, en definitiva, de las decisiones tomadas por el traductor. Por último, cabe destacar que este trabajo sólo abarca y puede inferir conclusiones y normas para un tipo concreto de problemas de traducción, así como para una pequeña parte de lo que comprenden los estudios en TAV y los Estudios de Traducción.

Sería muy recomendable llevar a cabo un estudio similar al que se presenta en torno a otros problemas de traducción de esta película 
para tener una visión más amplia del método, las estrategias y las técnicas usadas en la traducción y poder derivar normas de traducción más específicas. Este tipo de estudio se podría llevar a cabo, también, para otras películas de este mismo género o de este mismo director, para así poder favorecer más ampliamente a los Estudios Descriptivos de Traducción.

\section{Bibliografía}

AdAMs, M. (2009): Slang - The People's Poetry, Oxford Press, Indianapolis.

BASSNETT, S. (1998): "Researching Translation Studies: The Case for Doctoral Research", en BUSH, P. y MALMKJ/ER, K. (eds.) Rimbaud's Rainbow: Literary Translation in Higher Education, John Benjamins, Amsterdam y Philadelphia (105-18).

BELL, R. T. (1991): Translation and Translating, Theory and Practice, Longman, Londres.

Calvo Ferrer, J.R. (2010): "Análisis contrastivo de las escuelas lingüísticas de traducción y de la escuela de polisistemas aplicado al estudio del argot» en Tonos Digital. Revista electrónica de estudios filológicos, (20).

CAlZADA PÉREZ, M. (2007): El espejo traductológico: teorías y didácticas para la formación del traductor, Octaedro, Barcelona.

CATFORD, J.C. (1965): A Linguistic Theory of Translation: an Essay on Applied Linguistic, Oxford University Press, Londres.

ChAUME, F. (2004): Cine y traducción, Cátedra, Madrid.

CHE SUH, J. (2002): "Compounding Issues on the Translation of Drama/Theatre Texts» en Meta, (47/1: 51-57).

DUMAS, B.K., Y LIGHTER, J. (1978): «Is Slang a word for linguists?» en American Speech (53: 5-17).

EBLE, C. (1996): Slang and Sociability: In-Group Language among College Students, University of North Carolina Press, Chapel Hill y Londres.

ERIKSEN, M.H. (2010): Translating the use of slang- A study of microstrategies in subtitling with a view to researching the transfer of the use of slang from source text to target text with I Love You, Man as empirical example, including a study of the function of slang. Tesis doctoral de Aarhus School of Business, Aarhus University. 
EVEN-ZOHAR, I. (1999): "La posición de la literatura traducida en el polisistema literario» en IGLESIAS SANTOS, M. (ed.) Teoría de los

Polisistemas, Arco, Madrid (223-231).

FernÁNDEZ, R. y SAMANIEGo, E. (2002): "La variación lingüística en los Estudios de Traducción» en Epos: Revista de Filología, Madrid (18: 325342).

GaRCíA YeBRA, V. (1994): Traducción: historia y teoría, Gredos, Madrid.

GrahA, E.B. (2010): An Analysis of Slang Translation in the Subtitles of The Departed Movie. Tesis presentada en la Univesitas Pendidikan, Indonesia.

Hatim, B. E MASON, I. (1990): Discourse and the Translator, Longman, Londres.

- (1997): The Translator as Communicator, Routledge, Londres.

HOUSE, J. (1977): A Model for Translation Quality Assessment, Gunter Narr, Tübingen.

HURTADO ALBIR, A. (2001): Traducción y Traductología: Introducción a la traductología. Cátedra, Madrid.

LEECH, G. (1983): Principles of Pragmatics, Longman, Londres.

MARCO BORILLO J. (2001): "La descripción y comparación de traducciones: hacia un modelo integrador» en Sendebar, (12: 129152).

- (2002): El fil d'Ariadna: anàlisi estilística i traducció literària, Eumo, Vic.

MARTí Ferriol, J.L. (2010): Cine independiente y traducción, Tirant Lo Blanch, Valencia.

MARTínez SieRRA, J.J. (2008): Humor y traducción. Los Simpson cruzan la frontera, Publicacions de la Universitat Jaume I, Castelló de la Plana

MAYORAl Asensio, R. (1990): "Comentario a la traducción de algunas variedades de la lengua» en Sendebar (1: 35-46).

- (1997): La traducción de la variación lingüística. Tesis doctoral de la Universidad de Granada

- (1999): "La traducción de la variación lingüística» en Hermeneus: Revista de la Facultad de Traducción e Interpretación de Soria, Excma. Diputación de Soria, Soria (Número extraordinario 1: 1-219). 
- (2000): «Parámetros sociales y traducción» en Trans, (4: 111-20).

MUÑOz MARTín, R. (1995): Lingüística per a traduir, Eumo, Vic.

Newmark, P. (1988): A Textbook of Translation, Prentice Hall, Nueva York y Londres.

SPERBER, D. Y WiLSON, D. (1986): Relevance: Communication and Cognition, Blackwell, Oxford.

TouRY, G. (1999): «La naturaleza y el papel de las normas en la traducción" en Iglesias SANTos, M. (ed.) Teoría de los Polisistemas, Arco, Madrid (233-255).

VeRMEeR, H. (2000): «Skopos and Commission in Translational Action» en

VenUtI, L. (ed.) The Translation Studies Reader, Routledge, Nueva York (221-232).

VINAY, J. P. y DARBELNET, J. (1958): Stylistique comparée du français et de I'anglais. Didier, París.

WILLIS, H. (1964): Structure style usage: a guide to expository Writing, Holt Rinehart and Winston, Inc, Austin.

ZabAlBEASCOA, P. (1996): "La didáctica de la traducción: desarrollo de la competencia traductora» en Aproximaciones a la traducción, disponible en pdf en la dirección: http://cvc.cervantes.es/obref/aproximaciones/zabalbeascoa.htm [consultado en junio de 2011] 
